\title{
Qualidade de sementes de feijão caupi (Vigna unguiculata (L.) Walp.) produzidas em
}

\section{Paragominas, Pará}

\author{
Quality of cowpea seeds (Vigna unguiculata (L.) Walp.) produced inParagominas, Pará \\ Calidad de semillas de caupí (vigna unguiculata (1.) walp.) producidas en Paragominas, Pará
}

Samily Cristo Soares Barros ORCID: https://orcid.org/0000-0002-1630-5461 Universidade Federal Rural da Amazônia, Brasil E-mail: samilysoares98@gmail.com

Wayla Carolina Pimentel de Castro ORCID: https://orcid.org/0000-0002-3424-0905 Universidade Federal Rural da Amazônia, Brasil E-mail: waylacarolina15@gmail.com

Henry Albert Werner

ORCID: https://orcid.org/0000-0002-1373-9766 Universidade Federal Rural da Amazônia, Brasil E-mail: henrywerner.hw@gmail.com

Karen Gabriele Batista de Morais ORCID: https://orcid.org/0000-0003-2587-2932 Universidade Federal Rural da Amazônia, Brasil Email: karengabriele75@gmail.com

Milena Pereira da Costa Esteves ORCID: https://orcid.org/0000-0002-6139-1725 Universidade Federal Rural da Amazônia, Brasil E-mail: milenacostaj5@gmail.com

Tamires Lima Nunes

ORCID: https://orcid.org/0000-0003-1713-3339 Universidade Federal Rural da Amazônia, Brasil E-mail:tamireslima.agro@gmail.com

Hemilli Taynara Gomes da Cruz ORCID: https://orcid.org/0000-0001-9955-2822 Universidade Federal Rural da Amazônia, Brasil E-mail: hemillicruz18@gmail.com

Roni de Azevedo ORCID: https://orcid.org/0000-0003-3283-5013 EMBRAPA Amazônia Oriental, Brasil E-mail: roni.azevedo@embrapa.br

Vanessa Mayara Souza Pamplona ORCID: https://orcid.org/0000-0002-2461-2103 Universidade Federal Rural da Amazônia, Brasil E-mail: vanessa.pamplona@ufra.edu.br

Bárbara Rodrigues de Quadros ORCID: https://orcid.org/0000-0001-7052-4326 Universidade Federal Rural da Amazônia, Brasil E-mail: barbara.quadros@ufra.edu.br

\begin{abstract}
Resumo
A produção de sementes de feijão caupi na entressafra no município de Paragominas pode ser uma alternativa viável, tanto pelo potencial de crescimento dessa região, como pela proximidade aos agricultores locais e pela possibilidade de desenvolvimento e adaptação de cultivares as condições climáticas locais. Dessa forma, o presente trabalho foi desenvolvido com objetivo de avaliar a qualidade de sementes de cultivares de feijão caupi produzidas em Paragominas- Pará, a fim de avaliar a adaptabilidade das cultivares no município. O experimento foi disposto em delineamento inteiramente casualizado, com quatro cultivares e cinco repetições. Foi avaliada a qualidade física (peso de mil sementes, grau de umidade e dano mecânico), qualidade fisiológica (teste de germinação, primeira contagem da germinação, envelhecimento acelerado, condutividade elétrica, emergência de plântulas em campo e índice de velocidade de emergência das plântulas) e a qualidade sanitária das sementes (teste em papel filtro). Os dados obtidos foram submetidos à ANAVA, para os dados que não apresentaram distribuição normal, aplicou-se a transformação de Box-Cox, e quando diferenças significativas foram encontradas entre as cultivares, as respectivas médias foram comparadas pelo teste de Tukey. Os resultados obtidos nesse trabalho mostraram que é possível a produção de
\end{abstract}


sementes com alta qualidade física, fisiológica e sanitária em Paragominas. As sementes das cultivares 3 e 1 respectivamente, obtiveram melhores resultados em relação as demais cultivares analisadas, apresentando menores índices de danos mecânicos, maior percentual de germinação e vigor e menor incidência de fungos.

Palavras-chave: Vigor; Germinação; Sanidade.

\begin{abstract}
The production of cowpea seeds in the off-season in the municipality of Paragominas maybe a viable alternative, both by the growth potential of this region, as by the proximity to local farmers and the possibility of development and adaptation of cultivars to local climatic conditions. Thus, the present work was developed with the objective of evaluating the seed quality of cowpea bean cultivars produced in Paragominas, Pará, in order to assess the adaptability of cultivars in the city. The experiment was arranged in an entirely randomized design, with four cultivars and five repetitions. It was evaluated the physical quality (thousand seeds weight, humidity degree and mechanical damage), physiological quality (germination test, first count of germination, acceleratedaging, electrical conductivity, seedling emergence in the field and seedling emergence speed index) and seed health quality (test on filter paper). The data obtained were submitted to ANOVA by Shapiro-Wilk and Lilliefors the test, and homogeneity of variances by Levene's test. For data that did not show normal distribution, the Box-Cox transformation was applied test and when significant differences were found between cultivars, the respective means were compared by the Tukey test. The results obtained in this work are possible to produce seeds with high physical, physiological and sanitary quality in Paragominas. The seeds from cultivars 3 and 1 respectively, obtained better results in relation to the other cultivars analyzed, presenting lower rates of mechanical damage, a higher percentage of germination and vigor and lower incidence of fungus.
\end{abstract}

Keywords: Vigor; Germination; Health.

\title{
Resumen
}

La producción de semillas de caupí fuera de temporada en el municipio de Paragominas puede ser una alternativa viable, tanto por el potencial de crecimiento en esta región, como por la cercanía a los agricultores locales y la posibilidad de desarrollar y adaptar cultivares a los locales. condiciones climáticas. Así, el presente trabajo se desarrolló para evaluar la calidad de semillas de cultivares de caupí producidos en Paragominas, Pará, con el fin de evaluar la adaptabilidad de cultivares en el municipio. El experimento se organizó en un diseño completamente al azar, con cuatro cultivares y cinco repeticiones. Se evaluó la calidad física (peso de mil semillas, grado de humedad y daño mecánico), calidad fisiológica (prueba de germinación, primer conteo de germinación, envejecimiento acelerado, conductividad eléctrica, emergencia de plántula en campo eíndice de velocidad de emergencia de plántula) y sanitario. calidad de las semillas (prueba en papel de filtro). Los datos obtenidos fueron sometidos a ANOVA mediante la prueba de Shapiro-Wilk y Lilliefors, y homogeneidad de varianzas por la prueba de Levene. Para los datos que no mostraron distribución normal, se aplicó la transformación de Box-Cox, y cuando se encontraron diferencias significativas entre cultivares, las respectivas medias se compararon mediante la prueba de Tukey. Los resultados obtenidos en este trabajo mostraron que es posible producir semillas de alta calidad física, fisiológica y sanitaria en Paragominas. Las semillas de los cultivares 3 y 1 respectivamente, tuvieron mejores resultados en relación a los demás cultivares analizados, mostrando menores tasas de daño mecánico, mayor porcentaje de germinación y vigor ymenor incidencia de hongos.

Palabras clave: Vigor; Germinación; Salud.

\section{Introdução}

O feijão-caupi, conhecido como feijão-macassar ou feijão-de-corda, é uma leguminosa de ciclo curto, com ampla distribuição mundial. Apresenta grande importância para os povos das regiões Norte e Nordeste pelo seu alto potencial produtivo e excelente valor nutritivo, contribuindo para a melhoria da qualidade de vida da população de menor poder aquisitivo rural e urbana, isso devido ser uma espécie de alto valor proteico, fonte de tianina, niacina, aminoácidos e fibras diéticas, e sua simplicidade para produção e acessibilidade, baixo custo de produção e de mercado, tornou o feijão caupi uma grande fonte geradora de renda e emprego (Freire Filho et al., 2011).

Recentemente, a cultura tem se expandido para todo o Brasil, devido à adoção de cultivares melhoradas, como o porte da cultivar (ereto ou semiereto), favorecendo, assim, o cultivo nos sistemas mecanizados, possibilitando, com isso, uma inserção nos sistemas de produção tecnificados tanto como cultura principal como de safrinha, além do alto nível tecnológico empregado pelos produtores (Nunes, 2016). 
Para uma produção agrícola de qualidade, o uso de semente certificas é um dos insumos de maior importância, pois estas têm garantia de pureza genética e varietal. Além de serem originadas por processos controlados e supervisionados de produção que garantem características superiores quando comparadas as sementes de classe não certificada.

A qualidade e produtividade de sementes de sementes certificadas é refletida nos fatores que influenciam na sua capacidade germinativa e vigor, sendo consideradas de alta e boa qualidade as que possuem estes quesitos elevados, tratadas de modo apropriado, com boa aparência e grau de umidade adequado, e estas características equilibradas proporcionam maior homogeneidade de população e elevado vigor (Lacerda, 2007). Assim, a avaliação de atributos de qualidade da semente são componentes essenciais para o controle do seu uso, fornecendo informaçães para a detecção e solução de problemas durante o processo produtivo.

Embora seja grande os avanços no melhoramento genético e nas técnicas de manejo da cultura do feijão caupi, ainda há muito a ser feito, pois além do esforço dos programas de melhoramento, quando se compara o feijão caupi com o feijão comum (Phaseolus Vulgaris L.), percebe-se que o volume de estudos para o feijão caupi é bem menor, tal como, o número de cultivares recomendas ou lançadas comercialmente (Cordeiro, 2019).

Dessa forma, o presente trabalho foi desenvolvido com objetivo de avaliar a qualidade de sementes de cultivares de feijão caupi produzidas em Paragominas, Pará, a fim de avaliar a adaptabilidade das cultivares no município.

\section{Metodologia}

As sementes certificadas foram produzidas no campo experimental Empresa Brasileira de Pesquisa Agropecuária em Paragominas-Pará, a partir de sementes básicas de feijão caupi. Já os testes para avaliação da qualidade das sementes foram conduzidos no Laboratório e viveiro da Universidade Federal Rural da Amazônia também localizado no município de Paragominas. O município fica localizado no sudeste do Estado do Pará, situado a 2o 59' S e 47o 21' O, com altitude média de 89 m. O clima é classificado como Aw, segundo Köppen, com médias anuais de precipitação, umidade relativa e temperatura de $1.743 \mathrm{~mm}, 81 \%$ e $26,3{ }^{\circ} \mathrm{C}$, respectivamente, verificando-se no período de julho a novembro baixa disponibilidade hídrica (Alves, 2014).

O experimento foi realizado em delineamento inteiramente casualizado, com quatro cultivares (identificadas como Lote 1, Lote 2, Lote 3 e Lote 4), em cinco repetições de 50 sementes cada. Cada tratamento (lote) foi beneficiado separadamente e as sementes foram extraídas manualmente das vagens e armazenadas em sala refrigerada sob temperatura média de $15^{\circ} \mathrm{C}$.

Para determinação da qualidade física da semente avaliou-se: o teor de água das sementes pelo método da estufa a 105 ${ }^{\circ} \mathrm{C} \pm 3$, durante 24 horas; o peso de 1000 sementes, calculado pela multiplicação por 10 do peso médio obtido nas repetições (Brasil, 2009); e o dano mecânico (ruptura do tegumento), pelo teste de hipoclorito de sódio (Embrapa, 2017).

Avaliou-se a qualidade fisiológica pelos testes de: germinação, onde foram distribuídas sementes sobre duas folhas de papel tipo germiteste umedecido com água destilada, cobertas com uma terceira e organizadas em forma de rolo. O teste teve duração de 8 dias e foi realizado em germinador tipo Biochemical oxygen demand - B.O.D, regulado para o regime de temperatura constante de $25^{\circ} \mathrm{C}$ e os resultados expressos em porcentagem de plântulas normais; primeira contagem de germinação foi realizada ao quinto dia após a semeadura das sementes (Brasil, 2009); condutividade elétrica, realizada pelo método de massa, leitura da condutividade elétrica em condutivímetro Digimed DM3 e resultados expressos em $\mu \mathrm{S} . \mathrm{cm}^{-1} \cdot \mathrm{g}^{-1}$ microsiemens por centímetro por grama (Dutra et al., 2006); envelhecimento acelerado em cada amostra de sementes foi distribuída em tela suspensa no interior de caixa plástico $(11$ x 11 x 3,5 cm), contendo $40 \mathrm{ml}$ de água destilada na parte inferior da caixa. 
Estas foram mantidas em câmara de germinação do tipo Biochemical Oxygen Demand (B.O.D.), regulada a $42{ }^{\circ} \mathrm{C}$, durante 48 horas (Dutra \& Teófilo, 2007). Após esse período, as sementes foram colocadas para germinar e avaliadas pela contagem das plântulas normais no quinto dia após a semeadura; emergência de plântulas conduzido em viveiro coberto com tela de sombrite preta de malha 50\%. A semeadura foi realizada em bandejas de plástico contendo areia como substrato e porcentagem de emergência de plântulas normais foi computada diariamente (Brasil, 2009); índice de velocidade de emergência de plântulas, calculado conforme Maguire (1962); e teste de tetrazólio realizado segundo metodologia proposta por Oliveira et. al., 2018, onde avaliou-se a localização e intensidade de coloração dos tecidos embrionários, presença e localização de danos e, as sementes foram classificadas em viáveis vigorosas, viáveis não vigorosas e não viáveis, (Brasil, 2009)

E por fim avaliou-se, a qualidade sanitária das sementes foi pelo método do papel-filtro ou "blotter test", utilizando-se metodologia de Henning (2015) com 100 sementes por tratamento, divididas em cinco subamostras contendo 20 cada, colocadas sobre duas folhas de papel mata borrão esterilizadas e umedecidas com água destilada autoclavada, dentro de caixas plásticas do tipo "gerbox" desinsfestadas com hipoclorito de sódio (1,05\%). A incubação foi realizada à temperatura de aproximadamente $20 \pm 2^{\circ} \mathrm{C}$, em regime de 12 horas de iluminação com lâmpadas fluorescentes, alternadas com 12 horas de escuro, durante sete dias. No final do teste, as sementes de cada tratamento foram analisadas individualmente quanto à incidência de fungos. Os resultados foram expressos em porcentagem.

A análise dos dados foi realizada por meio da análise de variância (ANAVA) seguindo o delineamento inteiramente ao acaso, para a validação da ANAVA foi realizada a verificação dos pressupostos de normalidade dos resíduos, por meio dos testes de Shapiro-Wilk e homogeneidade de variâncias pelo teste de Levene. Para os dados que não apresentaram distribuição normal, aplicou-se a transformação de Box-Cox. Quando diferenças significativas foram encontradas, as médias foram comparadas pelo teste de Tukey. Em todos os testes adotou-se $\alpha=0,05$. Os dados foram analisados com o auxílio do software $\mathrm{R}$ (versão 3.6.3), por meio dos pacotes: Agricolae, Car, Nortest, Fpp, Mass e forestmangr.

\section{Resultados e Discussão}

Os lotes analisados apresentaram diferenças significativas entre si para todas as variáveis de qualidade física. Os dados médios obtidos quanto às variáveis de qualidade física das sementes avaliadas estão dispostos na Tabela 1.

Tabela 1- Média \pm desvio padrão das variáveis de qualidade física (Teor de água, Peso de Mil Sementes - PMS e Dano mecânico).

\begin{tabular}{cccc}
\hline \multirow{2}{*}{ Lotes } & \multicolumn{3}{c}{ Média \pm desvio padrão das variáveis } \\
\cline { 2 - 4 } & Teor de água $(\%)$ & PMS (g) & Dano mecânico (\%) \\
\hline 1 & $7,50 \pm 0,42 \mathrm{~b}$ & $203,92 \pm 7,73 \mathrm{c}$ & $39,60 \pm 12,12 \mathrm{~b}$ \\
2 & $7,78 \pm 0,25 \mathrm{ab}$ & $285,33 \pm 6,92 \mathrm{a}$ & $21,60 \pm 6,07 \mathrm{c}$ \\
3 & $8,60 \pm 1,07 \mathrm{a}$ & $63,9 \pm 3,94 \mathrm{~d}$ & $26,00 \pm 8,25 \mathrm{bc}$ \\
4 & $8,18 \pm 0,23 \mathrm{a}$ & $233,65 \pm 8,3 \mathrm{~b}$ & $77,60 \pm 3,85 \mathrm{a}$ \\
\hline
\end{tabular}

Médias seguidas por letras iguais não diferem entre si pelo teste de Tukey (5\% de probabilidade). Fonte: Autores (2021).

O teor de água das sementes variou entre 8,6 e 7,5 \%, destacando-se a maiores umidades obtidas nos lotes 3 e 4 (tabela1). Informações de pesquisas recomendam que o feijão-caupi seja armazenado com teor de umidade igual a $13 \%$ (Embrapa, 2017). Neste trabalho, no entanto, a umidade das sementes foi quantificada após dois meses de armazenamento em condições ambientais controladas. Segundo Marcos Filho (2015), o grau de umidade das sementes sofre flutuações com a 
umidade relativa do ar, por meio da troca de vapor d'água entre as sementes e o ambiente, de vez que estas apresentam elevada capacidade higroscópica.

É relevante destacar a importância do baixo teor de água encontrado neste experimento para o controle de fungos de armazenamento e deterioração da semente (Maria, 2013). Entretanto, recomenda-se o manuseio das sementes nas operações de beneficiamento, com umidade de 13\%, a fim de evitar suscetibilidade à danos mecânicos por trincamento, ocasionado pela perda excessiva de água.

O PMS foi maior para o lote 2 que apresentou 221,43g a mais que o lote 3 de menor PMS, com apenas 63,9g (Tabela 1), isso se explica devido as características físicas da cultivar do lote 3, dentre as outras cultivares testadas apresenta menor tamanho, refletindo também no seu peso. O peso de mil sementes é um dado importante que pode nos fornecer um indicativo da qualidade das sementes, bem como gerar informações para calcular a densidade de semeadura (Brasil, 2009).

Segundo Nunes (2016), o elevado peso de mil sementes pode ser um dos indicadores de vigor das sementes. Sementes bem nutridas (mais pesadas), durante sua formação, apresentam maiores quantidades de reservas em relação às sementes menos nutridas (mais leves), consequentemente, maior vigor elas terão, o que torna essa variável de suma importância, pois, geralmente, é utilizada para cálculo de densidade de semeadura, e para pressupor a qualidade das sementes, estado de maturação e sanidade. Carvalho e Nakagawa (2012), salientam que sementes maiores possuem maior quantidade de reserva e são, consequentemente, mais vigorosas.

Nos resultados de dano mecânico pelo teste de hipoclorito, o lote 4 apresentou maior porcentagem de ruptura de tegumento com $(77,60 \%)$, seguida do lote $1(39,60 \%)$, lote $3(26 \%)$ e lote $2(21,60 \%)$, conforme a tabela 1 . O teste de hipoclorito de sódio, revelara a ocorrência e incidência de danos mecânicos, permitindo os ajustes necessários na forma de colher o feijão caupi e possibilitara a decisão do destino do lote colhido, pois, se o índice de dano mecânico ultrapassar $10 \%$ neste teste, não se recomenda a utilização para semente (Vilarinho, 2010).

Os altos índices de DM nas sementes nesta pesquisa, podem ser atribuídos ao processo de debulha, que foi realizada por "batedura", visto que o feijão-caupi é tradicionalmente colhido manualmente, vagem por vagem, e debulhado por meio de bateção. O impacto da batida, provoca rachaduras no tegumento, favorecendo a entrada de microrganismos, nem sempre provocando a morte, mas, frequentemente, reduzindo o vigor das plântulas. Esse processo, está restrito às pequenas propriedades e à pesquisa. Nas médias e grandes propriedades, há uma diversificada combinação de práticas que agilizam a colheita e o beneficiamento, primando pela manutenção da qualidade da semente (Smiderle, et. al., 2009).

Os lotes analisados também apresentaram diferença significativa entre si para todas as variáveis de qualidade fisiológica. Os dados médios referentes às variáveis fisiológicas das sementes analisadas encontram-se nas Tabelas 2 e 3.

Tabela 2 - Média \pm desvio padrão das variáveis de qualidade fisiológica (Germinação, primeira contagem - PC e Condutividade - CE).

\begin{tabular}{cccc}
\hline \multirow{2}{*}{ Lotes } & \multicolumn{3}{c}{ Média \pm desvio padrão das variáveis } \\
\cline { 2 - 4 } & Germinação $(\%)$ & PC $(\%)$ & C.E (Microssimes) \\
\hline 1 & $96,80 \pm 3,03 \mathrm{ab}$ & $93,20 \pm 5,40 \mathrm{a}$ & $225,54 \pm 11,05 \mathrm{~b}$ \\
2 & $84,80 \pm 11,1 \mathrm{~b}$ & $74,00 \pm 11,66 \mathrm{~b}$ & $172,05 \pm 15,34 \mathrm{c}$ \\
3 & $98,00 \pm 2,45 \mathrm{a}$ & $96,80 \pm 2,28 \mathrm{a}$ & $641,50 \pm 39,92 \mathrm{a}$ \\
4 & $93,20 \pm 8,56 \mathrm{ab}$ & $87,20 \pm 13,60 \mathrm{ab}$ & $195,60 \pm 15,96 \mathrm{bc}$ \\
\hline
\end{tabular}

Médias seguidas por letras iguais não diferem entre si pelo teste de Tukey (5\% de probabilidade). Source: Authors (2021). 
Na variável germinação, o lote 3 apresentou maior valor de germinação (98\%), seguida dos lotes 1,4 com 96,80\% e 93,20\%, respectivamente (Tabela 2). Todos os lotes apresentaram porcentagem de germinação acima de 80\%, que é o valor mínimo comercial estabelecido pela legislação (Chagas, 2018). Costa (2018) e Arruda et al. (2009), aos estudarem genótipos de feijão-caupi, também obtiveram porcentagem de germinação acima de $80 \%$.

A primeira contagem de germinação é considerada um teste de vigor, no qual sementes com melhor desempenho fisiológico germinam em menor tempo. Os lotes 1 e 3 apresentaram os maiores valores de germinação em cinco dias (93,20\% e 96,80\% respectivamente), sem diferença estatística, conforme apresentado na Tabela 2. Nunes (2016), avaliando a porcentagem de estimativa da primeira contagem de germinação de sementes de feijão-caupi em função da população de plantas, concluiu que a qualidade inicial das sementes avaliadas estava acima de $90 \%$, evidenciando que as sementes produzidas apresentavam alta qualidade fisiológica, sendo a primeira contagem de germinação eficiente para diferenciar vigor das sementes submetidas a diferentes populações de plantas.

Segundo Schuch e outros (2000), o teste de primeira contagem de germinação indica que as sementes que apresentam maiores porcentagens de plântulas normais, na primeira avaliação, são mais vigoras, por apresentarem maiores velocidades nos processos metabólicos, maiores taxa de crescimento, consequentemente, emissão mais rápida e uniforme da raiz primária na germinação. Entretanto, para Marcos Filho (1987), a primeira contagem de germinação é um teste que apresenta baixa sensibilidade para a diferenciação de lotes de sementes em diferentes níveis de vigor.

O teste de condutividade elétrica apresenta alto potencial de uso no contexto de avaliação do vigor das sementes em programas de controle de qualidade. As sementes que apresentam menor lixiviação de solutos e consequentemente menor valor de condutividade elétrica são as mais vigorosas. Está diretamente ligado com a integridade das membranas celulares (Batista et al., 2012). O lote 2 obteve o menor valor de condutividade elétrica (172,05 mS.cm.g), sendo, portanto, considerados de maior vigor pela menor lixiviação de íons da semente para a solução em função da menor degradação das membranas (Tabela 2).

Tabela 3- Média \pm desvio padrão das variáveis de qualidade fisiológica (Envelhecimento Acelerado- EA, Emergência de plântulas - EP e Índice de velocidade de emergência de plântulas - IVE).

\begin{tabular}{cccc}
\hline \multirow{2}{*}{ Lotes } & \multicolumn{3}{c}{ Média \pm desvio padrão das variáveis } \\
\cline { 2 - 4 } & EA $(\%)$ & EP $(\%)$ & IVE \\
\hline 1 & $84,00 \pm 15,03 \mathrm{ab}$ & $60,80 \pm 18,74 \mathrm{~b}$ & $7,32 \pm 2,56 \mathrm{~b}$ \\
3 & $60,00 \pm 17,44 \mathrm{~b}$ & $70,00 \pm 4,00 \mathrm{~b}$ & $8,29 \pm 2,00 \mathrm{~b}$ \\
4 & $99,20 \pm 1,79 \mathrm{a}$ & $97,60 \pm 3,29 \mathrm{a}$ & $11,48 \pm 0,99 \mathrm{a}$ \\
\end{tabular}

Médias seguidas por letras iguais não diferem entre si pelo teste de Tukey (5\% de probabilidade). Source: Authors (2021).

No teste de envelhecimento acelerado conforme a Tabela 3, a maior germinação após o período de estresse por alta temperatura e umidade que as sementes foram submetidas, o lote com melhor desempenho foi o 3 com 99,20\%, sendo também estatisticamente semelhante aos lotes 1 e 4 .

O bom desempenho do lote 3 após teste de EA, é reflexo dos elevados percentuais deste mesmo lote no teste padrão de germinação (Tabela 2). As sementes menos vigorosas geralmente são mais afetadas em sua capacidade de produzir plântulas normais e apresentam baixa germinação. Isso pode ser analisado devido o aumento da taxa de deterioração das sementes, quando foram expostas a níveis adversos de temperatura e umidade relativa durante o processo de envelhecimento acelerado, ocasionando a perda desse vigor (Almeida, 2018).

O vigor de sementes do lote 3 também é observado quando se observa os resultados da emergência de plântulas $(97,60 \%)$ e o índice de velocidade de emergência de plântulas em viveiro $(11,48)$, conforme mostra a Tabela 3. 
Ainda que os resultados de testes de germinação apresentem alto grau de confiabilidade pela possibilidade de reprodutibilidade dos resultados e utilização para fiscalizar o comércio, quando se trata do uso de lotes para fins de semeadura em campo, os resultados de emergência das plântulas costumam ser menores que os da germinação em laboratório. Isso ocorre porque o teste de germinação é conduzido sob condições ótimas e padronizadas expressando o máximo potencial do lote. Entretanto, como o destino final das sementes é o campo, estandes rápidos e uniformes são o foco dos produtores. Desse modo, a emergência das plântulas é um dos principais parâmetros para avaliação da qualidade fisiológica das sementes (Marcos Filho, 2015).

De acordo com Araújo Neto et al., 2014, as sementes de menor tamanho apresentam maior IVE devido as sementes menores necessitarem de menor quantidade de água para serem embebidas e germinar. Silva et al 2014, aponta que existem diferenças de vigor entre os genótipos em termos de maior e menor velocidade de germinação e observou que o maior IVE do genótipo de feijão caupi Rosinha possui também características de sementes menores. Essa afirmação, confirmou-se neste trabalho, devido a cultivar do lote 3 apresentar menor tamanho de sementes, menor peso e maior IVE.

Já a análise de variância do parâmetro de qualidade fisiológica teste de tetrazólio não apresentou resultados significativos quando se avaliou os percentuais de semente viável, semente viável não vigorosa e semente não viável. A Tabela 4, mostra as médias e desvio padrão da viabilidade dos lotes avaliados pelo teste de tetrazólio.

Tabela 4 - Média \pm desvio padrão das variáveis do Teste de Tetrazólio (V-semente viável; VNV- semente viável não vigorosa; e NV- semente não viável).

\begin{tabular}{cccc}
\hline \multirow{2}{*}{ Lotes } & \multicolumn{3}{c}{ Média \pm desvio padrão das variáveis } \\
\cline { 2 - 4 } & $\mathbf{V}(\boldsymbol{\%})$ & VNV $(\%)$ & $\mathbf{N V}(\boldsymbol{\%})$ \\
\hline 1 & $67,20 \pm 12,21 \mathrm{a}$ & $12,40 \pm 10,9 \mathrm{a}$ & $20,40 \pm 9,1 \mathrm{a}$ \\
2 & $62,00 \pm 18,49 \mathrm{a}$ & $28,80 \pm 13,54 \mathrm{a}$ & $9,20 \pm 7,16 \mathrm{a}$ \\
3 & $78,80 \pm 6,57 \mathrm{a}$ & $14,80 \pm 10,26 \mathrm{a}$ & $8,80 \pm 7,56 \mathrm{a}$ \\
4 & $63,60 \pm 7,27 \mathrm{a}$ & $26,80 \pm 7,82 \mathrm{a}$ & $10,00 \pm 3,16 \mathrm{a}$ \\
\hline
\end{tabular}

Médias seguidas por letras iguais não diferem entre si pelo teste de Tukey (5\% de probabilidade). Source: Authors (2021).

O teste de tetrazólio, avalia a viabilidade e vigor dos lotes, bem como apresenta o diagnóstico das causas pela redução da qualidade, como danos mecânicos, danos por umidade e danos de percevejos, que são os principais problemas que afetam a qualidade fisiológica da semente. Esse diagnóstico aponta problemas de redução de qualidade da semente, identificando seus pontos de origem, e permitindo ações corretivas, resultando na produção de sementes de alta qualidade (Oliveira, 2018)

Neste experimento, o percentual de sementes viáveis dos lotes, foi inferior aos percentuais de germinação. Os resultados dos testes de tetrazólio e germinação geralmente coincidem, porém pode-se identificar diferenças consideráveis, isso porque, no teste de tetrazólio, somente o embrião é avaliado, não considerando a influência das estruturas externas das sementes nos resultados do teste de germinação, devido a possíveis infestações com patógenos no lote (Abbade;2014).

Algumas pesquisas têm apresentado que um dos principais problemas que causam a redução da qualidade das sementes são os altos índices de danos mecânicos, que geralmente propiciam percentuais de descarte de lotes com prejuízos consideráveis para o setor sementeiro brasileiro (Uhde;2014). Como já discutido anteriormente, as sementes sofreram considerável dano mecânico (Tabela 1) pela debulha por bateção, o que provavelmente contribuiu para a baixa viabilidade dos lotes quando se examinou os embriões pelo teste de tetrazólio. Mas apesar disso, não houve comprometimento a germinação dos lotes. 
Os dados de qualidade sanitária não apresentaram diferença significativa entre os lotes analisados. Os resultados médios da qualidade sanitária das sementes estão dispostos na Tabela 5.

Tabela 5- Média \pm desvio padrão da variável sementes contaminadas no teste de sanidade.

\begin{tabular}{cc}
\hline Lotes (Tratamento) & Sementes Contaminadas $(\boldsymbol{\%})$ \\
\hline 1 & $7,00 \pm 8,37 \mathrm{a}$ \\
2 & $8,50 \pm 6,71 \mathrm{a}$ \\
3 & $6,50 \pm 6,52 \mathrm{a}$ \\
4 & $12,50 \pm 24,14 \mathrm{a}$ \\
\hline
\end{tabular}

Médias seguidas por letras iguais não diferem entre si pelo teste de Tukey (5\% de probabilidade). Source: Authors (2021).

De acordo com a instrução normativa 45/2013 do Ministério de Agricultura, Pecuária e Abastecimento (MAPA), o percentual máximo admitido de sementes contaminadas de feijão caupi é de 3\%, ou seja, os percentuais apresentados na tabela 5 estão acima da recomendação permitida de contaminantes pelo MAPA.

Nas análises realizadas observou-se maior incidência de fungos do gênero Fusarium sp., muito comum em regiões brasileiras produtoras, devido a possibilidade de ocorrência de chuvas frequentes durante as fases de maturação e colheita da semente. Segundo Gomes (2008), existem espécies desse gênero que não são patogênicas e que podem ocorrer com relativa frequência, não tendo nesse caso, muita importância para cultura. Por outro lado, as espécies Fusarium oxysporum e Fusarium solani são importantes para a cultura, podendo ocasionar doenças como fusarioses prejudiciais, capazes de provocar sérias perdas de produção, pois a alta patogenicidade do agente causal, sua transmissibilidade pelas sementes e a capacidade de sobreviver no solo, pode causar inibição na germinação das sementes, e mesmo as que germinarem apresentam crescimento do fungo sobre os cotilédones e folhas primárias, além de necrose na radícula, mesmo na ausência do hospedeiro específico.

O controle do Fusarium em feijão deve ser realizado empregando medidas integradas, destacando-se rotação de culturas, o uso de sementes sadias e a resistência genética. Esse agrupamento de medidas precisa ser reavaliado em plantios sob Sistema Plantio Direto (SPD), que apesar de proporcionar diversos benefícios quanto à conservação do solo e da água, também proporciona um ambiente favorável ao desenvolvimento de patógenos habitantes do solo, como o F. oxysporum f.sp. phaseoli (FOP) (Souza, 2008).

\section{Conclusão}

Os resultados atingidos neste trabalho levam a firmar que é possível a produção de sementes com elevada qualidade física, fisiológica e sanitária em Paragominas, mesmo nas condições tropicais que a região apresenta.

As sementes das cultivares do lote 3 e 1 respectivamente, obtiveram melhores resultados em relação aos outros lotes analisados, apresentando maior percentual de germinação e vigor, menores índices de danos mecânicos e menor incidência de fungos.

É importante que seja realizado outros estudos com intuito de consolidar as informações sobre a avaliação da qualidade de sementes produzidas na região, que servirão como orientação tanto para o corpo acadêmico quanto para os agricultores. 


\section{Referências}

Abbade, L. C., \& Takaki, M. (2014). Teste de tetrazólio para avaliação da qualidade de sementes de Tabebuia roseoalba (Ridl.) Sandwith- bignoniaceae, submetida ao armazenamento. Revista Árvore, 38(2), 233-240. Doi:https://doi.org/10.1590/S0100-67622014000200003

Almeida, A. P. V., Silva, E. S., Silva, V. P., Zago, W., \& Oliveira, B. S. (2013). Qualidade física, fisiológica e sanitária de sementes de feijoeiro (Phaseolus vulgaris L.) provenientes do município de Tangará da Serra- MT. Revista Centro Científico Conhecer, 9(17), 2241-2249. https://www.conhecer.org.br/enciclop/2017a/agrar/qualidade\%20de\%20sementes.pdf.

Almeida, F. C. S. (2018). Atributos fisiológicos de sementes de cultivares de feijão caupi após armazenamento em câmara fria. p 34. (Trabalho de Conclusão de Curso, Universidade Federal do Ceará, Fortaleza). http://www.repositorio.ufc.br/handle/riufc/39732.

Alves, L. W. R., Carvalho, E. J. M., Silva, L. G. T. (2014). Diagnóstico Agrícola do Município de Paragominas-PA, (21ª ed.): Embrapa Amazônia Oriental Belém-PA; https://www.infoteca.cnptia.embrapa.br/bitstream/doc/988380/1/BPD91.pdf.

Araújo Neto, A. C., Nunes, R. T. C., Rocha, P. A., Ávila, J. S., \& Morais, O. M (2014). Germinação e vigor de sementes de feijão-caupi (Vigna unguiculta (L.) Walp.) de diferentes tamanhos. Revista Verde de Agroecologia e Desenvolvimento Sustentável, 9(2), 71-75. https://www.gvaa.com.br/revista/index.php/RVADS/article/view/2216.

Araújo, D. G., \& Cunha, P. S J. (2019). Avaliação da qualidade fisiológica de sementes de Feijão-Caupi (Vigna Unguiculata (L.) Walp.). (Trabalho de Conclusão de Curso, Universidade Federal Rural da Amazônia, Belém/PA). Retirado de bdta.ufra.edu.br/jspui//handle/123456789/1020.

Arruda, K. R., Smiderle, \& O. J., Vilarinho, A. A (2009). Uniformidade de sementes de genótipos de feijão caupi cultivados em dois ambientes no Estado de Roraima. Revista Agro@mbiente On-line, 3(2), 122- 127. https://revista.ufrr.br/agroambiente/article/view/280.

Batista, N. A. S., Luz. P. B., Sobrinho, P. S., Neves, L. G., \& Krause W (2012). Avaliação da qualidade fisiológica de sementes de feijão-caupi pelo teste de condutividade elétrica. Revista Ceres, 59(4), 550-554. Doi: https://doi.org/10.1590/S0034-737X2012000400017;

Botelho, F. J. E., Guimarães, R. M., Oliveira, J. A., Evangelista, J. R. E., Eloi, T. A., \& Baliza, D. P. (2010). Desempenho fisiológico de sementes de feijão colhidas em diferentes períodos do desenvolvimento. Ciência e Agrotecnologia, 34(4), 900-907. Doi: https://doi.org/10.1590/S1413-70542010000400015.

Brasil, Ministério da Agricultura e Reforma Agrária. (2009). Regras para Análise de sementes. Brasília, DF: SNDP/DNDV/CLAV. https://www.gov.br/agricultura/pt-br/assuntos/insumos-agropecuarios/arquivos-publicacoes-insumos/2946_regras_analise_sementes.pdf

Carvalho, N. M., \& Nakagawa, J. (2012). Sementes: Ciência, Tecnologia e Produção. (5. ed): Funep. https://www.bdpa.cnptia.embrapa.br/consulta/busca?b=ad\&biblioteca=CPATSA\&busca=autoria:\%22NAKAGAWA,\%20J.\%20(Ed.).\%22.

Chagas, J. T. B., Farias, J. E. C., Souza, R. F., Júnior, S. P. F. \& Costa, M. G. S. (2019). Germinação e vigor de sementes crioulas de feijão-caupi. Centro Científico Conhecer, 5(9), 487-498. Doi: 10.18677/Agrarian_Academy_2018a48.

Cordeiro, K. A. (2019). Avaliação de linhagens melhoradas de feijão-caupi. (Doutorado, Universidade Estadual do Norte Fluminense, Campos dos Goytacazes, RJ). https://uenf.br/posgraduacao/producao-vegetal/wp-content/uploads/sites/10/2019/07/Tese-Kleberson.pdf.

DUTRA, A. S., \& Teófilo, E. M. (2007). Envelhecimento acelerado para avaliar o vigor de sementes de feijão caupi. Revista Brasileira de Sementes, 29(1), 193-197. Doi: https://doi.org/10.1590/S0101-31222007000100027.

EMBRAPA. (2017). Sementes de feijão-caupi de alta qualidade-Importância estratégica de seu emprego. http://www.bdpa.cnptia.embrapa.br.

França Neto, J. B. (1999). Vigor de sementes: conceitos e testes. (1ª ed.): ABRATES. https://ainfo.cnptia.embrapa.br/digital/bitstream/item/105000/1/Vigorde-sementes.pdf.

Freire Filho, F. R. (2011). Feijão-caupi: produção, melhoramento genético, avanços e desafios. (1ª ed.): EMBRAPA. https://www.alice.cnptia.embrapa.br/bitstream/doc/916831/1/feijaocaupi.pdf.

Gomes, D. P., Silva, G. C., Kronka, A. Z., Torres, S. B., \& Souza, J. R. (2008). Qualidade fisiológica e incidência de fungos em sementes de feijão caupi produzidas no Estado do Ceará. Revista Caatinga, 21(2), 165-171. Retirado de eriodicos.ufersa.edu.br/index.php/caatinga/article/view/727/348.

Henning, A. A. (2015). Guia Prático para identificação de fungos mais frequentes em sementes de soja. Brasília. (1. ed.): Embrapa. https://ainfo.cnptia.embrapa.br/digital/bitstream/item/125833/1/FOLHETO-Identificacao-de-fungos-OnLine.pdf.

Lacerda, A. L. S. (2007). Fatores que afetam a maturação e qualidade fisiológica das sementes de soja (Glycine max L.). Revista Brasileira de Sementes, 17(2), p. 132-137. http://www.infobibos.com.br/Artigos/2007_3/maturacao/index.htm.

Lopes, M. M., Prado, M. O. D., Sader, R.; Barbosa, R. M. (2010). Efeitos dos danos mecânicos e fisiológicos na colheita e beneficiamento de sementes de soja. Revista Biosci J., 27(2), 230-238. https://repositorio.unesp.br/bitstream/handle/11449/41152/WOS000290375000007.pdf?sequence=3\&isAllowed=y

Marcos Filho, J. (2015). Fisiologia de sementes de plantas cultivadas. https://www.abrates.org.br/.

Marcos Filho, J. (2015). Teste de envelhecimento acelerado. In: Krzyzanowski, F.C.; Vieira, R.D. https://repositorio.unesp.br/handle/11449/39476.

Marcos Filho, J., Cícero, S. M., \& Silva, W. R. (1987). Avaliação da qualidade das sementes. (1 ${ }^{\text {a }}$. ed.): FEALQ. https://www.scielo.br/j/sa/a/Xc73GvNbrq8JGCGzKfRjzXm/?lang=pt.

Maria, K. S. (2013). Potencial fisiológico de sementes armazenadas de feijão caupi (vigna unguiculata l. walp.) tratadas com óleo essencial de cravo da índia. (Mestrado em produção vegetal, Universidade Federal Rural de Pernambuco), Serra Talhada-PE. http://www.tede2.ufrpe.br:8080/tede2/handle/tede2/6170. 
Munizzi, A., Branccini, A. L., Rangel, M. A. S., Scapim, C. A., Barbosa, M. C., \& Albrecht, L.P. (2010). Qualidade de sementes de quatro cultivares de soja, colhidas em dois locais no estado de Mato Grosso do Sul. Revista Brasileira de Sementes, 32(1), 176-185. Doi: https://doi.org/10.1590/S010131222010000100020 .

Nunes, R.T.C. (2016). Qualidade fisiológica e produção de sementes de feijão-caupi submetidas a doses de molibdênio e população de plantas. (Mestrado em fitotecnia, Universidade Estadual do Sudoeste da Bahia) Vitória da Conquista -BA http://www2.uesb.br/.

Oba, G. C. (2016). Caracterização física de sementes de feijão-caupi durante o processo de secagem. (Dissertação, Universidade Federal da Grande Dourados, Dourados/MS). Retirado de http://repositorio.ufgd.edu.br/jspui/handle/prefix/583.

Oliveira, G. P., Camilli, E. C.; Morais, O. M. (2018). Metodologia para o teste de tetrazólio em sementes de feijão-caupi. Revista Investig. Agrárias, 20 (2), 110-117. Doi: https://doi.org/10.18004/investig.agrar.2018.diciembre.110-117.

R, core team r. (2020). A language and environment for statistical computing. R foundation for statistical compuing. URL https://www.R-project.org/.

Ribeiro. G. C. A. (2016). Qualidade de sementes de soja produzidas em Paragominas, Pará. (Trabalho de conclusão de curso, Universidade Federal Rural da Amazônia), Paragominas/PA. http://bdta.ufra.edu.br/jspui/handle/123456789/94.

Santos, F. G (2018). Sementes de feijão comercializadas e sementes salvas por produtores rurais. (Trabalho de Conclusão de Curso, Universidade Tecnológica Federal do Paraná, Pato Branco). http://repositorio.utfpr.edu.br/jspui/handle/1/13991.

Schuch, L. O. B., Nedel, J. L., Assis, F. N., \& Maia, M. S (2000). Emergência em campo e crescimento inicial de aveia preta em resposta ao vigor das sementes. Revista Brasileira de Agrociência, 6(2), 97-10. https://periodicos.ufpel.edu.br/ojs2/index.php/CAST/article/viewFile/326/321.

Silva, A. C.; Morais, O. M.; Santos, J. L., D’Arêde, L. O., \& Bento Silva, P. (2014). Componentes de produção, produtividade e qualidade de sementes de feijão-caupi em Vitória da Conquista, Bahia. Revista Agro@mbienteOn-Line, 8(3), 327-335. https://revista.ufrr.br/agroambiente/article/view/1894.

Silva, G. C., Delineide, P. G., Kronka, A. Z., Torres, S. B., \& Souza, J. R. (2008). Qualidade fisiológica e incidência de fungos em sementes de feijão caupi produzidas do estado do Ceará. Revista Caatinga, 21(2), 165 - 171. https://periodicos.ufersa.edu.br/index.php/caatinga/article/view/727.

Silva, F. H. A. (2015). Qualidade física, fisiológica e sanitária de sementes de feijão-caupi (vigna unguiculata 1. walp.) utilizadas no rio grande do Norte. (Mestrado em Fitotecnia, Universidade Federal Rural do Semi-Árido, Mossoró/RN). https://ppgfito.ufersa.edu.br/.

Silva, R. T. (2017). Qualidade fisiológica de sementes crioulas de Fabaceae. (Trabalho de Conclusão de Curso - TCC, Universidade Federal da Paraíba, AreiaPB). Retirado de https://repositorio.ufpb.br/.

Smiderle, O.J.; A cultura do feijão caupi na amazonia Brasileira. Lavras: EMBRAPA, 2009, cap.10. https://www.infoteca.cnptia.embrapa.br/infoteca/bitstream/doc/1065493/1/CulturaFeijaoCaupiBrasil.pdf.

Souza, E.D.T., Filho, A. C. C., \& Lobo Junior, M. (2008). Plantas de cobertura para controle da murcha de Fusarium em feijoeiro comum no sistema de plantio direto. Revista agropecuária Brasleira,43(8), 971-978. https://www.embrapa.br/busca-de-publicacoes/-/publicacao/216284/plantas-de-cobertura-paracontrole-da-murcha-de-fusarium-em-feijoeiro-comum-no-sistema-plantio-direto.

Tozzo, G. A., \& Peske, S. T. (2008). Morphological characterization of fruits, seeds and seedlings of pseudima frutescens (aubl.) radlk. (sapindaceae). Revista brasileira de sementes, 30 (2), 12-18. Doi: https://doi.org/10.1590/S0101-31222008000200002.

Uhde, S. (2014). Qualidade de sementes de soja avaliada pelo teste de tetrazólio: estudo de caso na empresa Dimicron. (Dissertação, Universidade Federal de Pelotas), Pelotas-RS. http://repositorio.ufpel.edu.br:8080/handle/prefix/3205.

Vilarinho, A. A. (2010). A cultura do feijão caupi na amazonia Brasileira. Lavras: EMBRAPA, 2010, capítulo 10. https://www.infoteca.cnptia.embrapa.br/infoteca/bitstream/doc/1065493/1/CulturaFeijaoCaupiBrasil.pdf. 